\title{
O Ato de Narrar e a Produção de Conhecimento em Psicologia Social
}

The Act of Narrating and the Production of Knowledge in Social Psychology

El Acto de Narrar y la Producción de Conocimiento en Psicología Social

\author{
Bruna Moraes Battistelli
}

Erica Franceschini

Flávia Luciana Magalhães Novais

Willian Guimarães

Universidade Federal do Rio Grande do Sul (UFRGS), Porto Alegre, RS, Brasil

\begin{abstract}
Resumo
Este artigo tem como objetivo discutir possibilidades teóricas no que tange às narrativas de mulheres, dando a ver um ensaio composto por plurais vozes. Partimos do campo da Psicologia Social, a fim de pluralizar suas referências diante daquilo que incide do/no tempo presente e que permeia as discussões pertinentes aos estudos de gênero. Para tanto, buscamos dialogar com autores e autoras que não costumam frequentar as páginas de textos desta área, tais como Conceição Evaristo. Nossa aposta metodológica pauta-se na ideia de narrar enquanto meio de produção de histórias de mulheres que, por sua vez, produzem conhecimento; elegemos um viés interseccional, numa discussão que leve em conta marcadores de raça, gênero e classe social. Deste modo, pactuamos com a ideia de que a produção de conhecimento em Psicologia possa se dar pela produção de novas narrativas, nas quais estas mulheres sejam reconhecidas como protagonistas e porta-vozes de suas próprias histórias.
\end{abstract}

Palavras-chave: mulheres; narrativas; produção de conhecimento; descolonizar.

\begin{abstract}
This article aims to discuss theoretical possibilities regarding women's narratives, presenting an essay composed of plural voices, starting from the field of Social Psychology, in order to pluralize their references in face of what affects / at the present time and which permeates the pertinent discussions to gender studies. Therefore, we seek to start a conversation with authors who do not usually partake on texts in this area, such as Conceição Evaristo. Our methodology focus is based on the idea of narration as a mean of reproducing stories of women who, in turn, generates knowledge; we present their narratives through an intersectional bias, whether in a discussion that takes into account markers of race, gender and/or social class. As such, we agree with the idea that generating knowledge in Psychology
\end{abstract}


can happen through bringing to light new narratives, in which these women are recognized as protagonists and spokespeople of their own stories.

Keywords: women; narratives; knowledge production; decolonize.

\section{Resumen}

Este artículo tiene como objetivo discutir posibilidades teóricas con respecto a las narrativas de mujeres, mostrando un ensayo compuesto de voces plurales. Comenzamos, por lo tanto, desde el campo de la psicología social, para pluralizar sus referencias frente a lo que afecta / en la actualidad y lo que impregna las discusiones pertinentes a los estudios de género. Por lo tanto, buscamos dialogar con autores que generalmente no visitan las páginas de textos en esta área, como Conceição Evaristo. Nuestro enfoque metodológico se basa en la idea de narrar como un medio para producir historias de mujeres que, a su vez, producen conocimiento; presentamos sus narrativas a través de un sesgo interseccional, ya sea en una discusión que tenga en cuenta los marcadores de raza, género y clase social. De esta manera, estamos de acuerdo con la idea de que la producción de conocimiento en Psicología puede ocurrir a través de la producción de nuevas narrativas, en las que estas mujeres son reconocidas como protagonistas y portavoces de sus propias historias.

Palabras clave: mujeres; narrativas; producción de conocimiento; descolonizar

\section{Introdução}

Maria não deixava de observar atentamente a respiração de Francisca. Sentada há mais de duas horas se questionava se seria esse o ritmo do coração de sua bebê. Sabia que algo estava acontecendo há alguns dias... Ela andava mais quieta, chorava menos, dormia mais. Cansada, pediu uma dispensa à sua patroa que, mesmo relutante, lhe concedeu. Depois de algumas horas na fila da UBS lhe explicaram que ali não era o lugar para o tipo de atendimento que a menina precisava. Disseram pra ela procurar a emergência do hospital; e que atendimento na UBS teria só para daqui duas semanas. Antes de se direcionar ao hospital, passou em casa, onde seu companheiro the indagou quanto a sua brancura. Ele a questionou sobre o que tinha acontecido pois estava branca como um papel. Olhando ele, ela apenas disse que precisava ir ao hospital...

Abrimos esta escrita com a narrativa de Maria e sua filha Chica: uma narrativa que inventamos, porém, que poderia ecoar a história de tantas outras 
mulheres. Mulheres que trabalham fora de casa, que cuidam de seus filhos e filhas, que acenam para que o ônibus pare, que enfrentam filas no supermercado, que sentem saudade da mãe que não veem há anos, que adoecem porque não contam com tratamento de esgoto, que acordam de madrugada para enfrentar a fila do posto de saúde. Mulheres que compartilham de experiências cotidianas, mas que podem não compartilhar das mesmas opressões: brancas, negras, pobres, ricas, cis, trans. São todas mulheres, contudo, os marcadores de raça e classe social que aqui são considerados indicam que cada mulher vive neste mesmo mundo de uma maneira distinta da outra. Justamente por esse entendimento prévio é que apostamos nas narrativas como um meio de dar a ver estas diferenças, em que dar a ver não significa comparar uma Maria à outra, mas sim, colocar em questão estes marcadores, retirando-os de um lugar essencializado (isto é, onde cada marcador já definiria $a$ priori, uma experiência) para poder, aliás, questionar opressões já naturalizadas e a realidade dos apagamentos históricosociológicos. Chamaremos essas mulheres de Maria, um nome popular no Brasil.

Preocupadas com o presente e com o desafio de pensarmos as contribuições da Psicologia Social para o mesmo, escrevemos. A construção de narrativas é nosso procedimento metodológico para pensarmos o que pode a Psicologia Social no presente. Se intentamos apresentar nossas Marias, também faz-se relevante dizer quem somos: uma mulher negra, duas mulheres brancas e um homem branco. Somos pesquisadoras/es brasileiras/os. Temos lugares de fala diferenciados: há, dentre nós, três pessoas que contam com o privilégio da brancura em suas vidas (um lugar confortável de privilégios), e isso não podemos negligenciar, visto que a branquitude é um construto ideológico de poder que nasceu no contexto do projeto moderno de colonização europeia (Steyn, 2004; Schucman, 2012).

Enquanto acadêmicas/os, assumimos o desafio de ouvir e falar com outras vozes (Simas\& Rufino, 2019). Um diálogo construído no encontro; um exercício de aprender a ver, escutar, falar a partir de outros referenciais, com outras pessoas - o que implica em uma prática complexa de produção de conhecimento, considerando que estamos sempre à mercê de produzirmos novos "escorregões coloniais". Para isso, colocar em análise o marcador raça faz-se importante, sendo este fundante do processo colonizador com o qual a academia é forjada. Uma invenção colonial que nos subjetiva e pauta a 
produção de conhecimento. Como compreender o colonialismo (processo ainda inconcluso) que marca a constituição da Universidade e do pensamento brasileiro? Acreditamos que um caminho possível para a Psicologia Social seja apostar nas narrativas que evidenciem a multiplicidade dos sujeitos e de seus modos de existir. Por ora, damos foco às narrativas de mulheres. Narrativas construídas a partir de nossas experiências e vivências. Um exercício ficcional que se baseia em vivências que nos são próximas. Inspiramo-nos em autoras como Conceição Evaristo (2017, s/p) que no livro Insubmissas Lágrimas de Mulheres, indaga: "Invento? Sim, invento, sem o menor pudor. Então as histórias não são inventadas? Mesmo as reais, quando são contadas. [...] Entre o acontecimento e a narração do fato, alguma coisa se perde e por isso se acrescenta". Nossa inspiração busca por contar novas histórias; histórias que falem de como é possível estar/sobreviver ao tempo presente que vivenciamos.

\section{Escrita, narrativas e a questão do presente}

Maria-Velha e Tio Totó ficavam trocando histórias, permutando as pedras da coleção. Maria-Nova, ali quietinha, sentada no caixotinho, vinha crescendo e escutando tudo. As pedras pontiagudas que os dois colecionavam eram expostas à Maria-Nova, que escolhia as mais dilacerantes e as guardava no fundo do coração (Evaristo, 2017, p. 30).

Que histórias nós, pesquisadoras/es de Psicologia Social, temos colecionado? Assim como Maria-Nova, seguimos acolhendo narrativas dos encontros aos quais nos deixamos afetar, como pedrinhas que ganham espaço em nossas pesquisas, contudo, que nem sempre ganham um devido lugar na caixinha de nossos pensamentos. É preciso fazer as narrativas pensarem, assim como olhar para as histórias. Histórias que vivemos, que observamos, que nos são contadas por usuárias/os, amigas/os, colegas, conhecidas/os. Um exercício de escrever o presente com linhas variadas e múltiplas. Escrever para acolher, assim, torna-se uma de nossas intenções/inquietações.

Maria-Nova, que ficava ali "escutando tudo", nos dá uma primeira pista a este exercício narrativo a que nos propomos: é preciso aprender a ouvir, à medida que escutar novas vozes, por vezes, demanda que desaprendamos a captar 
apenas o que nos parece mais familiar, o que a Grande História sempre evocou: o conhecimento colonial herdado de uma Europa branca e cisheternormativa. Um exercício nada simples e que nos exige vigilância quanto às linhas que escrevemos, como narramos e como nos localizamos e localizamos nossas narrativas. Assim, achamos importante dizer que nossas mulheres percorrem espaços sociais distintos: uma Maria é branca e pobre, ela busca um serviço de saúde, no qual lhe pedem protagonismo; a outra é uma estudante universitária negra e de classe média que tem a porta de serviços ofertada quando coloca-se diante do elevador. Maria atreve-se a escrever como Maria da Conceição que, assim como Maria-Nova, colecionam histórias. Mas será que suas histórias são acolhidas? E se são, como é este acolhimento? Narrar e acolher, dois verbos que nos surgem quando somos convocadas a pensar acerca do tempo presente e das possíveis contribuições da Psicologia Social para o mesmo.

Nossas narrativas têm um objetivo explícito: diversificar as referências no campo da Psicologia Social no qual nos ancoramos, com o intuito de abrasileirar a discussão proposta. Amefricanizar, como nos pede Lélia Gonzalez (1988), ao forjar uma unidade de vivências de povos que foram dizimados - tanto de maneira literal quanto culturalmente - por colonizadores europeus nas Américas. Valorizar suas vivências, religiosidades e narrativas é também colocar em xeque uma história tida como oficial. Logo, não estamos nos propondo a interpretar a história das mulheres que pedem passagem, sequer estamos falando de interpretar alguma vivência específica. Ao convocar as narrativas de Marias, pensamos em dar abertura às novas histórias, ponderando sobre o modo como estas têm sido contadas por nós, acadêmicos. Que uso fazemos das histórias que emergem em nossas pesquisas?

Assumimos uma escrita que passa por questões relacionadas a gênero, raça e classe social; uma escrita, pois, que evoca uma perspectiva interseccional, já que alude à multiplicidade de diferenciações que os marcadores imputam na produção destes sujeitos. Queremos elucidar que a interseccionalidade permeia nossa reflexão sobre o papel da branquitude na escuta das vozes de mulheres que trazemos e que nos levam a problematizar os mecanismos que (comumente) produzem conhecimento, bem como, a partir de nosso lugar de pesquisadores, refletir sobre o que temos produzido. Como já mencionamos, 
ocupamos a Psicologia Social de lugares diferentes, portanto, nossos privilégios e opressões pelas quais passamos nos acompanham em nosso processo de pesquisa. Como nossas Maria(s), a experiência de estar neste texto, é pautada por muitas nuances.

Para tanto, pedimos licença para apontar a importância desta escrita ser perpassada pela teoria interseccional, popularizada por KimberléCrenshaw (1989) - inicialmente, no âmbito do Direito - sendo propagada por feministas negras estadunidenses numa conjuntura na qual eram invisibilizadas pelas posições hegemônicas das mulheres brancas e dos homens negros, à medida que a branquitude e a masculinidade hegemônicas são padrões normativos que orientam a estrutura opressora. De acordo com a autora, a interseccionalidade coloca em interação dois ou mais eixos da subordinação: "ela trata especificamente da forma pela qual o racismo, o patriarcalismo, a opressão de classe e outros sistemas discriminatórios criam desigualdades básicas que estruturam as posições relativas de mulheres, raças, etnias, classes e outras" (Crenshaw, 2002, p. 177). Desse modo, a interseccionalidade utiliza os marcadores como afirmação na busca pelos direitos, sem os posicionar nas margens da sociedade, fazendo-se necessário entender que tanto a estrutura colonial quanto seus desdobramentos opressões e privilégios - agem de modos diferentes sobre os sujeitos. Ademais, concordamos com Carla Akotirene (2018) ao compreender que mesmo oprimidos por uma academia branca e colonial, ainda temos a possibilidade de cometermos violências com as Marias que encontramos no nosso percurso-pesquisa. Pois, como a própria autora diz:

\footnotetext{
Nem toda mulher é branca, nem todo negro é homem, nem todas as mulheres são adultos heterossexuais, nem todo adulto heterossexual tem locomoção política, visto a geografia do colonialismo limitarem as capacidades humanas (...) além disso, a interseccionalidade estimula o pensamento complexo, a criatividade e evita a produção de novos essencialismos
} (Akotirene, 2018, p. 40).

Vale dizer, diante deste cenário, que escrever acompanhadas por mulheres e sobre mulheres não é um exercício de exclusão, como muitos podem entender, mas, um processo, também, de escolha: uma escolha por aquelas que muito podem nos ensinar e dizer, contudo, pouco espaço ocupam em nossos textos, uma vez que mulheres são, com frequência, silenciadas e suas histórias acabam sendo narradas 
pelo outro (homem, branco, heterossexual com forte influência do Norte global). Diante disso, queremos criar frestas para as histórias mal contadas ou não contadas de mulheres, como as que convocam Gloria Anzaldúa (2000) à escrita e que a faz questionar a si mesma sobre o que a levaria a escrever: "escrevo para registrar o que os outros apagam quando falo, para reescrever as histórias mal escritas sobre mim, sobre você. Para me tornar mais íntima comigo mesma e consigo. Para me descobrir, preservar-me, construir-me, alcançar autonomia" (Anzaldúa, 2000, p. 232).

Neste âmbito, ademais, o próprio ato de escrever ganha contornos interseccionais posto que escritores/as brancos/as e até mesmo pesquisadores/as brancos/as escrevem como se ocupassem este "lugar por direito", como um lugar natural em um exercício ainda bastante colonizado de produção de conhecimento. Ser branco no Brasil é ser a representação hegemônica, o sujeito universal com o qual ainda estamos pactuadas/os e que se apresenta "como norma, ao mesmo tempo em que como identidade neutra, tendo a prerrogativa de fazer-se presente na consciência do seu portador, quando é conveniente, isto é, quando o que está em jogo é a perda de vantagens e privilégios"
(Silva, 2017, p. 28). Neste contexto, para criar narrativas e indagar o que pode a Psicologia Social, precisamos olhar para aquilo que nos permite, hoje, escrever quer seja, nosso privilégio acadêmico sendo que, somente assim vai ser possível escutar outras vozes e abrir a escrita para corpos e vidas que comungam de outras epistemologias e existências.

Não podemos esquecer que a trama na qual estamos inseridas/os tem um cenário específico: Brasil. Uma história contada a partir de um ideal pautado pelo mito da democracia racial. $\mathrm{O}$ racismo à brasileira pode ser entendido como um crime perfeito (Munanga, 2017) que, de acordo com o autor, mata os corpos e produz uma segunda morte com a produção de um silenciamento; uma armadilha necropolítica (Mbembe, 2003) que nos constitui e forja o genocídio de uma parcela da população. Um genocídio que deixa corpos pelo caminho, mas também deixa um rastro de silenciamentos. Histórias são silenciadas enquanto política de Estado. O subalterno fala e sempre falou, afirma Maria Paula Meneses (2008b), o que se faz necessário é que se criem os espaços de escuta para estas falas. 
Maria ia para terapia. Nunca ninguém havia a tratado efetivamente mal, mas sentia uma certa apreensão nos olhares alheios. Já estava acostumada a ser tratada com diferença em ambientes predominantemente brancos. Sempre sentiu-se desconfortável quando precisava acessar este bairro "chique" da cidade. Sentia um silencioso controle de quem pode (ou espera-se) transitar por ali. Antes de ir para a consulta viu uma feirinha de artesanato. Chegando perto das barracas notou que nenhum dos vendedores lhe deu atenção. Cansada de esperar que alguém que lhe atendesse, resolveu seguir adiante. Cumprimentou educadamente o porteiro que se levantou para abrir a porta de um dos elevadores. Maria precisou de alguns segundos para compreender que ele havia aberto a porta do elevador de serviço. Deu alguns passos para trás e explicou que estava indo à consulta com uma terapeuta. $O$ porteiro se mostrou constrangido, dizendo que ali mulheres negras eram faxineiras. Após um pedido de desculpas, Maria seguiu para sua sessão de terapia. $O$ assunto daquele dia foi as muitas pequenas agressões racistas a que Maria vivia no cotidiano (...) Na rua, lembrou-se novamente da feirinha, tinha gostado de um colar. Esperou pelo vendedor que ignorou a sua presença. Irritada, chamou por ele e pediu o preço. A pessoa lhe informou meio sem vontade. Comprou o objeto, mesmo com toda a resistência em ser atendida. Não tinha sido a primeira e nem seria a última vez que passaria por uma situação dessa. Voltaria àquela rua independente dos olhares e gestos racistas.

Abordar o racismo é voltar a essas diferentes ruas e produzir reflexão sobre a colonialidade a qual estamos submetidas/os. Escrever sobre e com mulheres em contexto brasileiro é dialogar, aliás, com Maria da Conceição Evaristo de Brito, um dos maiores nomes da literatura brasileira, uma mulher negra que nasceu em Belo Horizonte, em 1946. Maria da Conceição, mais conhecida como Conceição Evaristo é a mulher que nos ensina sobre a arte de narrar e a potência contida no ato de contar histórias. Escrever com Maria da Conceição, e torná-la presente em nosso texto, é lembrar a força das histórias e a implicação com a vida que a/o contadora/contador precisa ter. Ao escrever, Conceição Evaristo, assim como outras escritoras negras, subvertem um sistema que, previamente, a coloca no lugar da infâmia, no lugar de não ter lugar. Ela, mulher negra e pobre, requisita um lugar para si e passa a ocupar: a literatura, as escolas, as prateleiras de nossas casas 
com suas narrativas de vida e de morte, inculcando uma política de existir, pelo direito de ter vivido e de viver.

\section{Maria(s): por uma política de vida}

Escolhemos abrir nossos ouvidos a histórias de mulheres que criam frestas no agora, mulheres que falam (mesmo que as instituições insistam em não escutar). Chegamos ao presente abarrotadas de inquietações que requisitam novas narrativas. Se pudéssemos inferir certa analogia sobre as vidas de brasileiras como Maria, acerca dos modos como suas histórias são inscritas no mundo, no decorrer dos séculos, poderíamos dizer que sempre vivemos sob o jugo de uma grande borracha. Queremos dar ênfase ao fato de que foram e são inúmeras as borrachas que lançam suas grandes mãos para sufocar certas narrativas, implicando em um desenfreado apagamento de palavras e de vozes, tornadas esquecimento, tornadas estatísticas. Abrir os ouvidos seria, assim, uma possibilidade de criar novas memórias. Contudo, isto somente pode ser possível se, antes de tudo, analisarmos que nós mesmos produzimos apagamentos.

Assim, com o objetivo de exercitar a escuta, precisamos nos ancorar no conceito de raça que ganha um lugar de destaque neste artigo, não apenas porque damo-nos conta da importância de discutir o incessante apagamento da história dos negros no Brasil, mas também, porque a ideia de raça é fruto da colonialidade a qual está pautada a ciência moderna, especialmente no século XIX, que culmina na hierarquização das pessoas baseada em características fenotípicas. Antônio Sérgio Alfredo Guimarães expressa que a ideia de "raça social" não abrange apenas o dado biológico, já que não haveria qualquer comprovação, no bojo científico, da existência da categoria racial, contudo, as raças são "plenamente existentes no mundo social, produtos de formas de classificar e de identificar que orientam ações dos seres humanos" (Guimarães, 1999, p. 153). Ações que aniquilam não apenas memórias, mas também vidas.

A descartabilidade tem corpo delineado, marcado por raça, gênero e classe social - marcas que delineiam a ideia de "minoria". Minoria, vale dizer, não faz referência a um conceito numérico, assim como, não se opõe a um pressuposto máximo. No Brasil, são mulheres, crianças, jovens e homens negras/os que compõem a massa que morre e é deixada para morrer. São essas/es, também os que sentem os efeitos da produção de precariedade de forma mais intensa. Como diz Elza Soares: 
"a carne mais barata do mercado é a carne negra" e se, o objetivo do mercado passa sempre por encarecer a oferta, o que vislumbramos é um embranquecimento destes corpos, difundidos de forma rotineira pela mídia.

$\mathrm{Eu}$ realmente gosto desta frase “quieto como é mantido". Esta é uma expressão oriunda da diáspora africana que anuncia o momento em que alguém está prestes a revelar o que se presume ser um segredo. Segredos como a escravidão. Segredos como o colonialismo. Segredos como o racismo (Kilomba, 2010, p. 177).

Nesta medida, verifica-se uma política de aniquilamento de corpos; constitui-se, assim, uma necropolítica (Mbembe, 2003). Evocamos este conceito, proposto pelo camaronês AchilleMbembe (2003), a fim de contextualizar o tempo presente como parte de um poder maior, ao qual o autor denomina de necropoder uma vez que este visa manter os circuitos de morte em nome da manutenção de uma governabilidade do tipo colonial (proveniente do pacto entre colonizador e colonizado) para a construção identitária de uma suposta "nação". Assim, a necropolítica diz respeito a uma epistemologia de ódio e violência, que cria, pela mídia e pelo consumo, corpos e populações matáveis (Mbembe, 2003) como meio para embasar práticas e discursos de violência explícitos, que têm ganhado cada vez mais força no âmbito social brasileiro. Os maiores alvos? O Atlas da violência de 2018 diz que são homens, jovens, negros, pobres.

A população negra brasileira nominada "minoria" é a que mais sofre. Trezentos anos de escravização, e os outros restantes pautados por violência, morte, negligência e apagamento. Grandes borrachas que seguem impondo-se, assim como quando a Maria que conhecemos como Conceição Evaristo, no ano de 2018, é indicada para ocupar uma cadeira na Academia Brasileira de Letras (ABL). Diante da iminente "ameaça" de uma escritora negra vir a alcançar um lugar de tanta estima, após as grandes repercussões de apoio à sua candidatura, vimos Conceição ser impedida de ascender à cadeira que fora ocupada pelo imortal Castro Alves. A ABL não permitiu Conceição de ganhar posição e, tal perda, para além da esfera pessoal da escritora, vem nos dizer de uma tentativa de apagamento na história da literatura produzida por mulheres negras, estas que, 
neste país, parecem ser impedidas de ocupar o lugar da imortalidade, isto é, um lugar na memória.

A resistência surge por frestas, aberturas produzidas pela força de uma população que mais do que reage, age enquanto é esmagada pela constituição de um Estado que insiste em massacrar e apagar pessoas negras e pobres. A própria Conceição Evaristo diz que não quer ser vista como a exceção à regra. A resistência é cotidiana, chega na universidade com as ações afirmativas, obrigando à academia colocar em discussão temas que antes eram relegados a um grupo pequeno de pesquisadoras/es. Vale lembrar que é justamente por essa disparidade que os vencedores sempre contaram a sua versão da história. No "Dossiê dos Mortos e Desaparecidos Políticos: Resgatando a Memória Brasileira" (1995), enuncia-se que "há várias maneiras de narrar a história de um país". Destas, existiria uma trama ainda não desatada, ou melhor, tornada esquecida na história do Brasil, conhecida como a "ótica dos vencidos".

A esta "política de esquecimento", como profere Soraia Ansara (2012), poderia se responder com o movimento de colocar-se ao lado dos vencidos, o que implica uma recusa na identificação com os heróis oficiais do "22 de abril de 1500", por exemplo, dos conquistadores portugueses e poderosos europeus que construíram uma civilização para os índios "selvagens" brasileiros. Como narramos o processo de escravização da população negra? Qual o lugar das mulheres negras na literatura brasileira? Interroga-nos Conceição Evaristo. Perguntas para as quais não encontramos respostas, mas que servem à reverberação de quem as ler. Reverberações que nos provocam a vislumbrar nosso lugar enquanto pesquisadores/as em Psicologia Social, aliás, como um lugar de privilégio que nos permite ter voz. Não obstante, novas perguntas surgem: com que violências pactuamos em nossas produções de conhecimento? Quantas portas são fechadas para mulheres negras? Que opressões e apagamentos produzimos quando não olhamos para nossa branquitude? Quando não colocamos em prática nossos discursos antirracistas? Seguimos com Carla Akotirene (2019, p. 50-51) quando esta profere, em tom de convocação: "cabe à identidade branca usar interseccionalidade para desconstruir a falsa vulnerabilidade uniformizada, demonstrar o contexto das branquitude, não incorrer de oportunismos fraudulentos no sistema de cotas raciais". 
Neste viés, encontramos as narrativas, não apenas como recortes ou imagens do pensamento; mas também como marcos de existências que resistem e que, antes de tudo, vêm nos interrogar deste lugar que ocupamos pesquisadoras/es em Psicologia Social sobre o que temos feito para sustar uma conversa entre sociedade e universidade, bem como, de que maneira é possível dar lugar de escuta aos sobreviventes sem apagar, ainda, a ínfima palavra que lhes resta. Se "o subalterno não pode falar", como aponta Spivak (2010, p. 126), como fazê-lo existir sem corpo e sem palavra? Grada Kilomba (2019) lembra-nos que o subalterno fala, mas que a colonialidade não consegue oferecer lugares de escuta. Quem cala, é calado, quem fala, quem é escutada/o é sempre resultado de um jogo de poder racial.

\section{O protagonismo e as histórias cotidianas de mulheres}

A primeira pergunta que lhe foi feita é se tinha convênio. Não tinha. Explicou pra moça da recepção o que estava acontecendo. Meia hora depois, uma residente analisou a situação e explicou que ela teria que esperar o atendimento "não urgente". E assim obedeceu. Nem percebeu quando the entregaram um panfleto falando das novas ameaças que o SUS estava enfrentando; guardou o mesmo. Sentia raiva de si, sentia raiva da espera, da falta de resposta. Atendimento "não urgente", por quê? Sentia-se desrespeitada, sentindo que a vida de sua filha valia menos do que a das crianças com convênio. Procurou o panfleto pra se distrair. $O$ panfleto pedia protagonismo dos usuários. Mas o que ela poderia fazer? Como ela teria algum papel na maneira que esse serviço é conduzido? Sentia-se uma mera espectadora, como nos programas de TV. Seria ela, então, a culpada do serviço não funcionar como deveria? Protagonista? Maria leu mais de uma vez essa palavra.

Na narrativa enunciada, à Maria é pedido protagonismo. Certamente, algo que ela não está acostumada; algo que ela não sabe definir muito bem: protagonizar. Como ser protagonista de sua própria vida se, incessantemente, sente-se sendo posta às margens? Nestas margens em que não encontra atendimento para sua filha, que não encontra dignidade no seu trabalho, que quando chove demais não pode sair de casa, que é barrada na entrada da loja, etc. Diante disso, uma pergunta reverbera em nossas cabeças: como temos contado a 
história de muitas Marias que encontramos em nossos trabalhos de campo na Psicologia Social? Nossas bibliotecas, artigos, referências bibliográficas, de maneira geral, tem gênero, cor e classe social. Falamos do saber menor, de pesquisar com, de igualdade de gênero, mas começamos a nos questionar se, no limite, estamos de fato conversando com nossas/os interlocutoras/es. Escrevendo este artigo, pensamos nos desafios para a produção de conhecimento atual e sobre a necessidade de falar através de referências mais diversas e próximas de muitas outras histórias permeadas por marcadores sociais. AvtarBrah (2006) afirma que os marcadores sociais não são absolutos e possuem profunda relação entre si. Logo, as experiências de ser homem/mulher, ser branco/negro implicam em categorias intrinsecamente relacionadas.

María Lugones, autora argentina e feminista decolonial, afirma o gênero como uma das formas de opressão colonial; uma categoria de dominação de ação fundamental na constituição da modernidade/colonialidade. Assim, a autora, ao questionar a parcialidade do conceito de colonialidade de poder, acrescenta o gênero como central para pensarmos $\quad$ b binômio modernidade/colonialidade (Lugones,
2014). De maneira resumida, aos pensadores/as da modernidade/colonialidade interessa identificar, informar, criticar os padrões de dominação que continuam presentes nas relações sociais, políticas, ecológicas, internas e internacionais, fundadas pelo sistema-mundo moderno. MaríaLugones (2014) diz que as mulheres indígenas e as mulheres negras não são representadas nem na categoria universal de "mulher" nem nas categorias de índio e negro. Assim, a autora afirma que existe um sistema de gênero que opta por ignorar as categorias de raça e classe em sua constituição.

Centrar-se numa análise descolonial permite expor os mecanismos de subjugação e dominação imbricados no pensamento colonial em relação a um projeto ocidental (norte global) sobre as relações de gênero e outros marcadores sociais da diferença. Nesse contexto, a natureza é evocada como um estado puro que não necessita problematização ou explicação, no qual as relações colonizadas que se dão sobre o gênero assumem um caráter de verdade (Vergueiro, 2015). Da mesma forma, Vergueiro relaciona a produção da branquitude com tais questões coloniais de gênero em que ambos se tratam de lugares não marcados, mas que 
se produzem pela reiteração do lugar de um "Eu" e de um "Outro". Nesse sentido, a ausência do reconhecimento da branquitude, como temática passível de ser problematizada, é estratégica para determinar um grupo como "Outro" a ser estudado.

Ao evocarmos as mulheres negras (e muitas delas latino-americanas), além de compreendermos que é necessário escutar quando "o lixo vai falar, e numa boa", como bem disse Lélia Gonzales (1984), reconhecemos outras possibilidades de vivências, narrativas e olhares. Lélia nos surge enquanto possibilidade de pensar a mulher negra no Brasil, mas também enquanto pensadora que se ateve com a temática da colonização. Ousamos afirmar: o lixo vai falar! E quando o lixo fala, ele faz emergir todo um novo olhar para o tempo presente, um olhar da resistência para resistir aos assombros que nos envolvem. Outrossim, reconhecer que o Estado contribui para o extermínio simbólico e literal de populações inteiras é o primeiro movimento de resistência.

Certas vozes nascem impossibilitadas de serem ouvidas. Uma das Marias que nos acompanham é pobre e branca, mas conta privilégios que a brancura lhe confere. Assim mesmo, não se sente protagonista de sua história ou vida. Maria é parte de uma maioria, não foi apagada por completo. $\mathrm{E}$ as mulheres negras? Para estas, relegamos lugares tais como: negligentes, masoquistas, dependentes, aproveitadoras, barraqueiras, etc. Lélia González, Sueli Carneiro e bellhooks são três mulheres que ousaram romper com os lugares previamente impostos às mulheres negras e com a lógica que as coloca enquanto pessoas que não sabem, portanto, que não produzem conhecimento. Mas, elas não podem ser a exceção que confirma a regra, como nos convoca a pensar Conceição Evaristo. Quem é silenciada/o pela produção de conhecimento da Psicologia no Brasil?

A população pobre brasileira, em grande parte, é composta de histórias de pessoas que, cotidianamente, perdem seus filhos e companheiros por conta de uma dita "Política de Segurança Pública". A esses sujeitos, que têm cor e classe social, são negados direitos de existência, liberdade e ancestralidade. Narrar a vida dessas mulheres e de suas famílias é entender que elas são negligenciadas pelo Estado em seu cotidiano, desde o não acesso a serviços de qualidade até o risco de morte que as cercam. São mulheres que precisam construir suas vidas para além do que o Estado lhe oferece. A desigualdade no Brasil é racializada, mesmo que as 
políticas públicas insistam em se dizer universais.

Para falar com/sobre Marias, é preciso descolonizar o pensamento. Descolonizar o pensamento, aqui, vem dizer sobre alguns pontos que listamos a seguir: 1) racializar as produções de conhecimento; 2) reconhecer os resquícios do mito da democracia racial que fazem do racismo brasileiro uma operação necropolítica violenta e eficiente, assim como; 3) reconhecer como a Psicologia ainda opera em uma lógica epistemicída. Bellhooks é quem questiona: "a partir de qual perspectiva política nós sonhamos, olhamos, criamos, agimos?" (hooks, 2019, p. 36). Para a autora, pensar em descolonizar é produzir novas imagens em resposta às imagens que o patriarcado supremacista branco criou para afirmar-se enquanto lógica dominante. Importante: bellhooks fala do lugar de mulher negra, pensando em possibilidades para pessoas negras. Enquanto produção de conhecimento, temos que ter cuidado com a captura e romantização que podemos construir sobre as afirmações dela.

Assim, o desafio seria criar alternativas, transformar imagens, questionar quais tipos de imagens é possível subverter, apresentar alternativas críticas e transformar visões de mundo (hooks, 2019, p. 37). Pensando a partir do que a autora propõe, entendemos que, para a Psicologia predominantemente branca, de referências produzidas e sustentadas por um arcabouço teórico embranquecido, é preciso uma análise mais profunda sobre sua branquitude, sobre as violências que coadunam com sua produção de conhecimento e sobre como podemos produzir novas imagens e narrativas. Produzir novas imagens, contar outras histórias, povoar o mundo de histórias (Meneses, 2008a; Tsallis\& Moraes, 2016) são objetivos que precisam estar em pauta na produção de pesquisas na área da Psicologia.

Descolonizar a produção de conhecimento opera, deste modo, na colonialidade a qual estamos mergulhados, sem nem mesmo nos darmos conta. Isso implica em fazer notar que o folheto que Maria recebe - aquele que lhe pede protagonismo - não requisita apenas que ela "tome as rédeas" da sua vida. O folheto desloca a ideia de responsabilidade: muitas vezes, reconhecer a necessidade de participação das/os usuárias/os no controle social das políticas públicas acaba por reforçar um sistema de dupla responsabilização a que pessoas em situações como a de Maria são chamadas a responder. Ao mesmo tempo em que ela é 
colocada em situação de precariedade extrema é responsabilizada por esta, e também passa a ser responsabilizada pela superação desta mesma precariedade, sem levarmos em conta a negligência estatal da qual Maria já é vítima.

Diante disso, compreendemos que as formas de acesso aos serviços, a qualidade dos mesmos e a urgência nesse acesso são diferentes quando dizem respeito às pessoas negras e às pessoas brancas. A precariedade é sentida de forma mais presente quando se é mulher e negra, são "vidas precárias", conforme explicita Judith Butler (2004) ao se referir às vidas cujas mortes não são choradas, já que nem mesmo, epistemologicamente, estas vidas foram registradas como vividas; são vidas que estão fora do reconhecimento social. Vidas negras sobre a qual a colonialidade incide com mais força. Maria, na busca por atendimento para sua bebê, revela a importância de discutir o espaço de precariedade alimentada pelo Estado, sem perder de vista a negligência que permeia as vidas precárias. A norma constituída para afirmar que tais sujeitos são dignos de cuidado é a mesma norma que afirma os limites daqueles que podem ser considerados humanos daqueles que não podem ser. O quão humano é considerado o bebê de Maria em suas necessidades?
Seria Chica um bebê branco ou miscigenado, já que do pai ainda não sabemos? Sabemos, contudo, que esta informação poderia mudar o modo como o bebê será tratado. Ao mesmo tempo, é importante expressar que chegar a um hospital já diz de um lugar de privilégio, considerando que muitos, nem mesmo lá chegam.

$\mathrm{O}$ valor da precariedade de certas vidas vão evidenciar-se nos diferentes apagamentos das marcas que as constituem. Trazer à cena a racialização da branquitude é reivindicar uma certa existência para essa marca e seus efeitos na constituição das ações do Estado. Afirmar que determinadas ações estatais vão conferir determinados graus de precariedades é contestar esse apagamento histórico ao direito à liberdade. Cabe, nesta conjuntura, produzir desvios. Cabe trazer ao palco as diferentes formas de vidas para ouvir suas próprias vozes e resguarda-lhes seu direito a uma existência plena, se é que um dia saberemos o que "existir plenamente" significa. Mesmo assim, insistimos em produzir novas imagens.

\section{Considerações finais: algumas provocações que ficam}


Quando recebeu um telefonema da diretora da escola do guri mais velho, Maria já sabia o que era. Já havia chamado atenção do rapaz, já havia dito para o pai dele se envolver. Tudo continuava igual. Um dia conversando com uma vizinha ouviu falar de um serviço chamado CRAS. Era um pouco longe de onde Maria morava, mas valia a tentativa. Era uma casa como as demais na comunidade. $\mathrm{Na}$ recepção, the encaminharam para uma outra sala. A funcionária que lhe acolhe apresenta-se como Maria e diz que faz parte da equipe de atendimento do CRAS. A mãe do rapaz. ri e explica que esse também é o seu nome. Homenagem às santas à parte, Maria explica a situação do seu filho enquanto a outra Maria a escuta. A funcionária do serviço lhe fez algumas perguntas sobre a história que estava sendo narrada, mostrando interesse no que estava sendo contado. Após Maria, a mãe, encerrar e permanecer em silêncio, Maria, a mulher do CRAS, lhe explica um pouco do funcionamento do serviço e lhe fez uma proposta. Gostaria que Maria voltasse com sua família em um encontro nos próximos dias para conversar sobre aquela situação com todos e os possíveis encaminhamentos. Maria saiu com uma sensação boa. Tinha entendido o que lhe falaram e tinha podido falar sem ser recriminada.

Maria encontra outra Maria que acolhe suas necessidades e escuta sua história. Sem querermos direcionar o CRAS como serviço ideal à escuta, afirmamos que o acolhimento não precisaria de uma política específica para fazer-se operar. Ofertar olhar, um abraço, um café não é apenas gestualizar uma rotina, mas sim, gestualizar novas moradas sensíveis. Com quem Maria pode compartilhar sua história, experimentar novos modos de existência, criar novas paisagens afetivas? São estas questões que fazem nossas práticas cotidianas tornaremse práticas de cuidado e é a este cuidado que apontamos quando abordamos as questões de gênero, raça e classe social neste artigo. Nossa outra companheira de texto, Maria (a estudante) segue com sua terapia. Certo dia, resolveu parar e conversar com o porteiro. Sentiu uma empatia pelo homem, pontos de histórias em comum. Ele contou, que era uma orientação da firma que trabalhava para abrir a porta do elevador de serviços para pessoas negras. Maria lhe contou que nem deveriam existir mais elevadores de serviço. Confessou que fica revoltado, mas precisava do dinheiro. Maria Conceição 
não entrou na Academia Brasileira de letras. Quem perdeu foi ela (a academia). Segue nos inspirando, contando histórias de vidas que importam e que merecem o cuidado com suas representações. Nos ensina que precisamos pensar nosso direito/privilégio de narrar e nossa implicação com as histórias que colocamos no papel. Se temos o privilégio de narrar, com quais histórias ocupamos nossas linhas, textos e artigos? María (a autora argentina e feminista) ajuda-nos a pensar que descolonizar, diz de um exercício de colocar nosso corpo e nosso pensamento em trânsito para novos lugares, para pensar e refletir acerca de nossas ferramentas de trabalho, para buscar por novas lógicas. Se utilizamos o termo "novo" ao invés de "outros", isto é porque não precisamos abandonar antigas referências, mas sim dobrá-las no seu uso de maneira a fazer sentido para os problemas que emergem e os que nos colocamos no tempo presente.

O desafio em ouvir diferentes vozes passa por reconhecer as multiplicidades de existências que, atravessadas pelas questões raciais, de gênero e/ou classe social, sofrem, a seu modo, apagamentos cotidianos e resistem, cada uma a sua maneira, a tais opressões. Dessa forma, compreendemos os muitos desdobramentos e enfoques possíveis a partir dessas reflexões que fazemos, relacionadas neste texto, ao epistemicídio negro, à necropolítica, ao racismo institucional, apenas para citar algumas dessas possibilidades. Finalizamos esta escrita com a sensação de que muito precisa ser aprofundado quanto ao que foi exposto. Enquanto ensaio teórico, nos pautamos pelos ecos que nossas questões deixam. Não temos o objetivo de encerrar tais discussões ou impor caminhos, mas sim propor aguçar o ouvido para a escuta de novas histórias e outras formas de escrevêlas. Ressaltamos, nestas últimas linhas que escrevemos, que não é papel de uma única área do conhecimento trilhar este caminho; nem mesmo acreditamos que este caminho deva ser trilhado meramente pelo campo acadêmico. Falamos em caminhos, encruzilhadas, em atalhos e desvios. Em acolhimento e escuta de histórias muitas que povoem o mundo e que permitam que adiemos o final deste, como nos sugere Ailton Krenak (2019). Cabe, por ora, contar histórias no presente para imaginar novos e, quem sabe, acolhedores futuros.

\section{Referências}

Akotirene, C.; Ribeiro, D. (2018). O que é intersecccionalidade? Coleção Feminismos Plurais, Belo Horizonte, MG: Letramento: Justificando. 
Akotirene,

C.

(2019).

Interseccionalidade. São Paulo: Pólen Livros. (Feminismos plurais).

Ansara, S. (2012). Políticas de memória x políticas de esquecimento: possibilidades de desconstrução da matriz colonial. Revista Psicologia Política, $12 \quad$ (24), 297311. Recuperado dehttp://pepsic.bvsalud.org/pdf/rpp/v 12n24/v12n24a08.pdf

Anzaldúa, G. (2000). Falando sobre línguas: uma carta para as mulheres escritoras do terceiro mundo. Estudos Feministas, 8, 229-236. Recuperado dehttps://periodicos.ufsc.br/index.ph p/ref/article/view/9880/9106

Brah, A. (2006). Diferença, diversidade, diferenciação. Cadernos Pagu, 26, p. 329-376. Recuperado de http://www.scielo.br/pdf/ref/v10n1/1 1636.pdf

Butler, J. (2004). Precariouslife. London: Verso.

Crenshaw, K. (2002). A interseccionalidade na discriminação de raça e gênero. Painel 1 Cruzamento: raça e gênero, 7-16. Recuperado

dehttp://www.acaoeducativa.org.br/f $\mathrm{dh} / \mathrm{wp}-$

$\underline{\text { content/uploads/2012/09/Kimberle- }}$ Crenshaw.pdf

Crenshaw, K. W. (1989). Demarginalizing the intersection of race and sex; a black feminist critique of discrimination doctrine, feminist theory and antiracist politics, University of Chicago Legal Forum, 139-167.
Evaristo, C. (2016). Histórias de leves enganos e parecenças. Rio de Janeiro: Editora Malê.

Evaristo, C. (2016). Insubmissas lágrimas de mulheres. Rio de Janeiro: Editora Malê.

Evaristo, C. (2017). Becos da memória. Pallas Editora.

Gagnebin, J. M. (2010). O preço de uma reconciliação extorquida. In E. Teles. $\&$ V.Safatle (Orgs.). O que resta da ditadura.São Paulo: Boitempo.

Instituto de Pesquisa Econômica Aplicada (IPEA). (2018). Atlas da Violência 2018. Rio de Janeiro: Ipea e FBSP.

Gonzalez, L. (1984). Racismo e sexismo na cultura brasileira. Revista Ciências Sociais Hoje, Anpocs, 223244. Recuperado

dehttps://edisciplinas.usp.br/pluginfil e.php/4584956/mod_resource/conten $\mathrm{t} / 1 / 06 \% 20$ \%20GONZALES\%2C\%20L\%C3\% A9lia\%20\%20Racismo_e_Sexismo_na_Cultur a_Brasileira\%20\%281\%29.pdf

Gonzalez, L. (1988). "A categoria político-cultural de amefricanidade". Tempo Brasileiro, Rio de Janeiro, 92/93, 69-82. Recuperado dehttps://negrasoulblog.files.wordpre ss.com/2016/04/a-categoriapolc3adtico-cultural-deamefricanidade-lelia-gonzales1.pdf

Guimarães, A. S. A. (1999). Racismo e anti-racismo no Brasil. Rio de Janeiro: Ed. 34.

hooks, b. (2019). Olhares Negros: raça e representação. São Paulo: Elefante. 
Kilomba, G. (2010). The Mask. Em Plantation Memories: Episodes of Everyday Racism. Münster: UnrastVerlag. 2. Auflage.

Krenak, A. (2019). Ideias para adiar o fim do mundo. Companhia das Letras.

Lugones, M. (2014). Rumo a um feminismo decolonial. Revista Estudos Feministas, 22(3), 935-952. Recuperado dehttps://periodicos.ufsc.br/index.ph p/ref/article/view/36755/28577

Mbembe,

A. (2003). Necropolitics.PublicCulture, 15, 1140. Recuperado dehttps://read.dukeupress.edu/publicculture/articleabstract/15/1/11/31714/Necropolitics ?redirectedFrom $=$ fulltext

Meneses, M. P. (2008a). Outras vozes existem, outras histórias são possíveis.Diálogos sobre Diálogos. Niterói: Grupalfa, UFF.

Meneses, M. P. (2008b). Mulheres insubmissas? Mudanças e conflitos no norte de Moçambique. Ex aequo, (17), 71-87. Recuperado dehttp://www.scielo.mec.pt/pdf/aeq/ $\underline{\text { n17/n17a05.pdf }}$

Munanga, K. (2017). As Ambiguidades do Racismo à Brasileira. Em Munanga, K.; Kon, N. M.; Silva, M. L. \&Abud, C. C. (Orgs.). O racismo e o negro no Brasil: questões para a psicanálise (pp. 33-44). São Paulo: Perspectiva.

Movimento Tortura Nunca Mais MTMN. (1995). Dossiê dos Mortos e Desaparecidos Políticos a partir de
1964. Recife/Pe: CEPE. Recuperado de

http://www.dhnet.org.br/dados/dossi ers/dh/br/dossie64/br/dossmdp.pdf

Schucman, L. V. (2012). Entre o "encardido", o "branco" e o "branquíssimo": raça, hierarquia e poder na construção da branquitude paulistana. [Tese de Doutorado], Instituto de Psicologia da Universidade de São Paulo.

Schwarcz, L. M. (2012). Nem preto nem branco, muito pelo contrário: cor e raça na sociabilidade brasileira. São Paulo: Claro Enigma.

Silva, P. E. (2017). O conceito de branquitude: reflexões para o campo de estudo. In: T. M. P. Müller \&L. Cardoso (Orgs.). Branquitude: estudos sobre a identidade branca no Brasil (pp. 19-31). Curitiba: Appris.

Simas, L. A. \& Rufino, L. (2019). Flecha no tempo. Rio de Janeiro, RJ: Mórula Editorial.

Spivak, G. C. (2010). Pode o subalterno falar? 1. ed. Trad. Sandra Regina Goulart Almeida; Marcos Pereira Feitosa; André Pereira. Belo Horizonte: Editora da UFMG.

Steyn, M. (2004). Novos matizes da "branquidade": a identidade branca numa África do Sul multicultural e democrática. Em Ware, V. (Org.). Branquidade: identidade branca $e$ multiculturalismo. Rio de Janeiro: Garamond.

Tsallis, A.C.; Moraes, M. (2016). Contar histórias, povoar o mundo: a escrita acadêmica e o feminino na ciência.Revista Polis e Psique, 6 (1), 39-50.

Recuperado 
dehttps://seer.ufrgs.br/PolisePsique/a $\underline{\text { rticle/view/61380/36655 }}$

Vergueiro, V. (2015). Por inflexões decoloniais de corpos e identidades de gênero inconformes: uma análise autoetnográfica da cisgeneridade como normatividade. Dissertação de mestrado. Universidade Federal da Bahia, Instituto de Humanidades, Artes e Ciências Professor Milton Santos, Salvador.

Bruna Moraes Battistelli é doutoranda no PPG de Psicologia Social e Institucional da UFRGS.

E-mail:brunabattistelli@gmail.com ORCID:http://orcid.org/0000-0003-0973$\underline{0934}$

Erica Franceschini é doutoranda no PPG Psicologia Social e Institucional UFRGS. E-mail:ericafranceschini@ hotmail.com ORCID:https://orcid.org/0000-0001-8443$\underline{5834}$

Flávia Luciana Magalhães Novais é doutoranda no PPG Psicologia Social e Institucional UFRGS.

E-mail:flanovais@gmail.com

ORCID:https://orcid.org/0000-0003-2184415X

Willian Guimarães é doutorando no PPG Psicologia Social e Institucional da UFRGS.

E-mail:willgaspar@gmail.com ORCID:https://orcid.org/0000-0003-1072$\underline{0290}$

Submissão: $28 / 01 / 2020$ 